\title{
Correction to: Avenues of Influence: the Relationship between Health Impact Assessment and Determinants of Health and Health Equity
}

Elizabeth Kelley Sohn • Lauren J. Stein • Allison Wolpoff • Ruth Lindberg • Abigail Baum • Arielle McInnis-Simoncelli • Keshia M. Pollack

Published online: 27 August 2018

(C) The New York Academy of Medicine 2018

\section{Correction to: J Urban Health}

https://doi.org/10.1007/s11524-018-0263-5

Please note that the correct name of the penultimate author of this article is "Arielle McInnis-Simoncelli", not "Arielle Mc-Innis Simoncelli" as presented in the article as originally published. The original article has been corrected.

The online version of the original article can be found at https://doi.org/10.1007/s11524-018-0263-5

E. K. Sohn $(\bowtie) \cdot$ L. J. Stein

Harder+Company Community Research, San Francisco, CA, USA

e-mail: ekelley@harderco.com
A. Wolpoff
Harder+Company Community Research, San Diego, CA, USA
R. Lindberg $\cdot$ A. Baum $\cdot$ A. McInnis-Simoncelli
Health Impact Project - The Pew Charitable Trusts, Washington, DC, USA
K. M. Pollack
Johns Hopkins Bloomberg School of Public Health, Baltimore,
MD, USA 